Check for updates

Cite this: RSC Adv., 2019, 9, 3345

\title{
Halide-free neodymium phosphate based catalyst for highly cis-1,4 selective polymerization of dienes†
}

Yixin Ren, ${ }^{a}$ Justin T. Miller, ${ }^{a}$ Stefanie T. Polderman, ${ }^{a}$ Trinh D. Vo, ${ }^{a}$ Adele C. M. Wallace, ${ }^{a}$ John Michael O. Cue, ${ }^{a}$ Sarah T. Tran, ${ }^{a}$ Michael C. Biewer ${ }^{a}$ and Mihaela C. Stefan (D) *ab

Neodymium-based Ziegler-Natta type catalytic systems are known to produce polydienes with high cis-1,4 content. It is generally believed that in Ziegler-Natta catalytic systems, a halide or pseudohalide, whether in the catalyst itself or a separate source, is required for the success of the polymerization. In this work, we have synthesized an unusual halide-free neodymium diethyl phosphate catalyst for diene polymerization. This neodymium complex combined with triisobutylaluminum (TIBA), formed a binary catalytic system and was used to polymerize $\beta$-myrcene. The catalytic system displays high stereospecificity and produces poly( $\beta$-myrcene) with $96 \%$ cis-1,4 content and a relatively narrow molecular weight distribution $\left(M_{w} / M_{n}=1.80\right)$. Also, kinetic studies indicated the catalytic system gives a pseudo-living polymerization. The block copolymer poly( $\beta$-myrcene)- $b$-poly(isoprene) was successfully synthesized by sequential monomer addition, further demonstrating the pseudo-living nature of polymerization with the neodymium diethyl phosphate catalyst.

Received 6th December 2018 Accepted 10th January 2019

DOI: $10.1039 / \mathrm{c} 8 \mathrm{ra10050k}$

rsc.li/rsc-advances

\section{Introduction}

High-quality elastomeric materials from the polymerization of dienes (butadiene and isoprene) are in high demand for industrial applications. ${ }^{1-3}$ Diene polymerization can result in polydienes with three different possible configurations: cis, trans, and vinyl. High cis-1,4 content leads to excellent elasticity, high fatigue and crack resistance, and low heat build-up in synthetic rubber. ${ }^{4,5}$ Additionally, studies have shown that the molecular weight distribution is strongly related to the physical properties of the synthesized polydienes, and narrow molecular weight distribution $\left(M_{\mathrm{w}} / M_{\mathrm{n}}<3.0\right)$ is generally desired to achieve better uniformity in vulcanization. ${ }^{6,7}$

Lanthanide-based Ziegler-Natta catalysts have drawn particular interest due to higher cis-1,4 microstructure (98\%) generated in the polymerization of 1,3-butadiene as compared to catalysts based on transition metals, such as titanium, cobalt, and nickel..$^{4,6-9}$ Among the lanthanide series, neodymium-based catalysts have been the focus of research due to their better catalytic activities and higher stereoregularity.,7,10,11 ZieglerNatta catalysts, including most neodymium catalysts, are generally shown to require halides for alkylation and activation.

${ }^{a}$ Department of Chemistry and Biochemistry, The University of Texas at Dallas, $800 \mathrm{~W}$. Campbell Rd., Richardson, TX 75080-3021, USA. E-mail: mci071000@utdallas.edu ${ }^{b}$ Department of Bioengineering, The University of Texas at Dallas, $800 \mathrm{~W}$. Campbell Rd., Richardson, Texas, 75080-3021, USA

$\dagger$ Electronic supplementary information (ESI) available. See DOI: $10.1039 / \mathrm{c} 8 \mathrm{ra} 10050 \mathrm{k}$
In many cases, the halides are present in the catalyst itself, resulting in a binary system (along with the alkylaluminum cocatalyst). These catalysts contain electron donor ligands such as isopropanol, ${ }^{12}$ tributyl phosphate,,$^{13}$ triethyl phosphate, ${ }^{14,15}$ and tetrahydrofuran (THF). ${ }^{16}$ In other cases, the catalysts do not have any halide atoms coordinated to the metal and require an additional halide source, such as $\mathrm{AlEt}_{2} \mathrm{Cl}$, forming a ternary catalytic system. These catalysts contain carboxylate ligands such as versatates, ${ }^{17,18}$ octanoates, ${ }^{19}$ and naphthenates. ${ }^{20}$ In recent studies, the halogens have been replaced with pseudohalogens, such as borohydrides, and the systems have retained effective catalytic activities. ${ }^{21,22}$

The catalytic systems without halides usually produce polydienes with low cis-1,4 content and broad molecular weight distribution. ${ }^{23,24}$ For example, Evans and co-workers studied the chloride effects in a neodymium carboxylate-based catalyst for isoprene polymerization and demonstrated that the catalytic system with a chloride source exhibited a narrower, monomodal molecular weight distribution $\left(M_{\mathrm{w}} / M_{\mathrm{n}}=2.9-13.5\right)$ as compared to the system without chloride, which had a much broader and bimodal molecular weight distribution $\left(M_{\mathrm{w}} / M_{\mathrm{n}}=\right.$ 14.3-19.8)..$^{23}$ Masuda et al. reported a halide-free binary system consisting of neodymium isopropoxide and methylaluminoxane which polymerized isoprene with only $92 \%$ cis-1,4 content. ${ }^{24}$

In this study, we report the synthesis of a halide-free neodymium diethyl phosphate complex obtained by azeotropic distillation. This complex, in combination with the cocatalyst triisobutylaluminum (TIBA), constitutes a new type of halide-free Ziegler-Natta catalytic system with high cis-1,4 
(96\%) selectivity and relatively narrow molecular weight distribution $\left(M_{\mathrm{w}} / M_{\mathrm{n}}=1.8\right)$ for the polymerization of $\beta$-myrcene. $\beta$ Myrcene (7-methyl-3-methyleneocta-1,6-diene, $\mathrm{C}_{10} \mathrm{H}_{16}$ ), was used for this study because it is an environmentally benign, biorenewable monomer derived from plants such as dill, thyme, and rosemary. ${ }^{25}$ The high cis-1,4 selectivity and narrow molecular weight distribution are directly influenced by the amount of co-catalyst present in the catalytic system. These results are in contrast to conventional Ziegler-Natta systems in which the halides are required for good performance. Kinetics experiments are performed to demonstrate the pseudo-living behavior of this catalytic system. The successful synthesis of the block copolymer poly( $\beta$-myrcene)- $b$-poly(isoprene) further demonstrates living behavior.

\section{Experimental section}

\section{Materials}

Reagents obtained from Sigma Aldrich Chemical Co., Inc.: $\mathrm{NdCl}_{3} \cdot 6 \mathrm{H}_{2} \mathrm{O}$ (99.9\%), triethyl phosphate (99.8\%), triisobutyl phosphate (TIBA, $25 \mathrm{wt} \%$ in toluene), and ethanol (absolute, Fisher Scientific) were used without further purification. The monomers $\beta$-myrcene (90\%) and isoprene (99\%) obtained from Aldrich were distilled over calcium hydride to remove stabilizer and moisture and were stored in a vial containing molecular sieves under nitrogen before use. Toluene (99.9\%, Aldrich) was distilled over sodium and benzophenone before use. All reactions were performed using Schlenk techniques under argon atmosphere.

\section{Characterizations}

${ }^{1} \mathrm{H},{ }^{13} \mathrm{C}$, and ${ }^{31} \mathrm{P}$ NMR spectra were recorded on a Bruker AVANCE III ${ }^{\mathrm{TM}} 500 \mathrm{MHz}$ NMR spectrometer at ambient conditions. Energy Dispersive X-ray spectroscopy (EDX) was performed on Zeiss-LEO Model 1530 Variable Pressure Field Effect Scanning Electron Microscope. The NMR samples were dissolved in $\mathrm{CDCl}_{3}$ or $\mathrm{D}_{2} \mathrm{O}$ purchased from Cambridge Isotope Laboratories. Peak multiplicity is abbreviated as: s (singlet), $\mathrm{d}$ (doublet), t (triplet), q (quartet), br (broad) with chemical shifts reported in ppm $(\delta)$. The number-average molecular weight $\left(M_{\mathrm{n}}\right)$ and polydispersity index (PDI) were determined using Size Exclusion Chromatography (SEC) on a Viscotek VE 3580 system equipped with Viscotek columns (T6000M) and a refractive index detector. Polystyrene was used as the calibration standard, and HPLC grade tetrahydrofuran was used as the eluent for the SEC. The crystal structure of the catalyst $\left[\mathrm{Nd}(\mu \text {-DEP })_{3}\right]_{x}$ was determined with a Bruker D8 Quest Kappa single crystal X-ray diffractometer.

\section{Synthesis of $\left[\mathrm{Nd}(\mu-\mathrm{DEP})_{3}\right]_{x}$}

The neodymium tris-diethyl phosphate complex was synthesized by azeotropic distillation under a nitrogen atmosphere. In a $100 \mathrm{~mL}$ round bottom flask, $\mathrm{NdCl}_{3} \cdot 6 \mathrm{H}_{2} \mathrm{O}(2.0114 \mathrm{~g}, 5.6 \mathrm{mmol})$ was first dissolved in $20 \mathrm{~mL}$ of absolute ethanol, and then $50 \mathrm{~mL}$ of anhydrous toluene was introduced to the flask. To the same flask, triethyl phosphate (TEP) (3.81 mL, $22.4 \mathrm{mmol}$ ) was added.
This system, which contains toluene, ethanol, and water, forms a ternary azeotrope. The ternary azeotrope (toluene-ethanolwater), which has a boiling point of $74.4{ }^{\circ} \mathrm{C}$, was removed until all of the water was removed from the reaction mixture. The binary azeotrope composed of toluene and ethanol (bp $\left.76.7^{\circ} \mathrm{C}\right)$ was then removed. The remaining toluene was removed, causing a light purple solid to precipitate. The precipitate was washed three times with diethyl ether and resulted in a 90\% yield. The synthesized polymeric complex is water, air, and thermally stable. The complex is water soluble and moderately soluble in $\mathrm{CHCl}_{3} .{ }^{1} \mathrm{H}$ NMR $\left(500 \mathrm{MHz}, \mathrm{D}_{2} \mathrm{O}\right): \delta(\mathrm{ppm}), 1.40(\mathrm{t}, 3 \mathrm{H})$, 4.22 (q, 2H). ${ }^{31} \mathrm{P}$ NMR (500 MHz, $\left.\mathrm{D}_{2} \mathrm{O}\right): \delta(\mathrm{ppm}), 19.30$. Anal. calcd. for $\mathrm{C}_{12} \mathrm{H}_{30} \mathrm{NdO}_{12} \mathrm{P}_{3}$ : C, 23.59; $\mathrm{H}, 4.50$. Found: $\mathrm{C}, 23.88 ; \mathrm{H}$, 5.01 .

\section{General procedures for synthesis of $\operatorname{poly}(\beta$-myrcene $)$}

The synthesis of poly( $\beta$-myrcene) and kinetic studies thereof was performed in a flame-dried $25 \mathrm{~mL}$ Schlenk flask under argon atmosphere. For a typical polymerization experiment, a molar ratio of $[\beta$-myrcene] : [Nd] : [TIBA] of $250: 1: 30$ was used. The catalyst $\left[\mathrm{Nd}(\mu-\mathrm{DEP})_{3}\right]_{x}(17.72 \mathrm{mg}, 0.03 \mathrm{mmol})$ and the cocatalyst TIBA $(0.83 \mathrm{~mL}, 0.88 \mathrm{mmol})$ were introduced to the Schlenk flask and stirred at the desired temperature for one minute. The distilled $\beta$-myrcene was then introduced to the reaction flask. Methanol was used to terminate the polymerization reaction. The synthesized polymer was washed several times with methanol and dried under vacuum overnight to remove the solvent completely before characterization. For the kinetic studies, aliquots were periodically withdrawn to estimate the monomer conversion using ${ }^{1} \mathrm{H}$ NMR and the SEC was used to determine the number average molecular weight and the polydispersity index. ${ }^{1} \mathrm{H}$ NMR $\left(500 \mathrm{MHz}, \mathrm{CDCl}_{3}\right): \delta(\mathrm{ppm})$, 1.60 (br, 3H), 1.68 (br, 3H), 2.06 (br, 8H), 5.13 (br, 2H). ${ }^{13} \mathrm{C} \mathrm{NMR}$ $\left(500 \mathrm{MHz}, \mathrm{CDCl}_{3}\right): \delta(\mathrm{ppm}), 17.70,25.68,26.81,26.98,30.64$, $36.94,124.49,124.68,131.19,139.02$.

\section{General procedures for chain extension experiment}

The chain extension experiment was carried out via sequential monomer addition with the monomer $\beta$-myrcene using the ratio of $[\beta$-myrcene 1$]:[\beta$-myrcene 2$]:[\mathrm{Nd}]:[\mathrm{TIBA}]=$ $150: 300: 1: 30$. To a dry Schlenk flask, $\left[\operatorname{Nd}(\mu \text {-DEP })_{3}\right]_{x}$ (31.40 mg, $0.052 \mathrm{mmol}$ ) and TIBA $(1.40 \mathrm{~mL}, 1.48 \mathrm{mmol}$ ) were introduced, the mixture was stirred for one minute under argon. The first batch of the monomer $(1.25 \mathrm{~mL}, 7.34 \mathrm{mmol})$ was then added to the reaction flask. Upon the complete consumption of the monomer which as confirmed by ${ }^{1} \mathrm{H}$ NMR, the second portion of monomer $(2.52 \mathrm{~mL}, 14.7 \mathrm{mmol})$ was introduced to the reaction mixture. The reaction was continued until all the monomer was consumed, and the reaction was terminated by precipitation of the polymer in methanol. The synthesized polymer was dried in the vacuum oven overnight for further characterization. ${ }^{1} \mathrm{H} \mathrm{NMR}\left(500 \mathrm{MHz}, \mathrm{CDCl}_{3}\right)$ : $\delta$ (ppm), 1.60 (bs, 3H), 1.67 (br, 3H), 2.05 (br, 8H), 5.12 (br, 2H). ${ }^{13} \mathrm{C}$ NMR (500 MHz, $\left.\mathrm{CDCl}_{3}\right): \delta(\mathrm{ppm}), 17.70,25.68,26.81,26.98$, $30.64,36.94,124.49,124.68,131.19,139.02$. 


\section{Synthesis of block copolymer poly( $(\beta$-myrcene)-b-poly(isoprene)}

Synthesis of poly( $\beta$-myrcene)- $b$-poly(isoprene) was performed in a $25 \mathrm{~mL}$ Schlenk flask under argon. $\left[\mathrm{Nd}(\mu-\mathrm{DEP})_{3}\right]_{x}(30.1 \mathrm{mg}$, $0.052 \mathrm{mmol})$ and TIBA $(1.45 \mathrm{~mL}, 1.50 \mathrm{mmol})$ were introduced to the reaction flask, and the reaction mixture was stirred for one minute. The first block of monomer ( $\beta$-myrcene) $(1.30 \mathrm{~mL}, 7.34$ $\mathrm{mmol}$ ) was added to the reaction flask. The monomer conversion was monitored using ${ }^{1} \mathrm{H}$ NMR. After complete consumption of the monomer ( $\beta$-myrcene), dry isoprene $(1.50 \mathrm{~mL}, 14.7$ $\mathrm{mmol}$ ) was introduced to the flask. The reaction continued until the complete consumption of isoprene. The reaction was then terminated in methanol, causing the polymer to precipitate as a white gel. $M_{\mathrm{n}}=15528 \mathrm{~g} \mathrm{~mol}^{-1}$ and PDI $=3.13 .{ }^{1} \mathrm{H}$ NMR $\left(\mathrm{CDCl}_{3}, 500 \mathrm{MHz}\right) \delta: 1.59$ (br, 3H), 1.67 (br, 6H), $2.04(\mathrm{br}, 12 \mathrm{H})$, $5.12(\mathrm{br}, 3 \mathrm{H})$.

\section{Results and discussion}

A neodymium catalyst bearing phosphate ligands $\left[\operatorname{Nd}(\mu-\mathrm{DEP})_{3}\right]_{x}$ was successfully synthesized by the ligand exchange method by azeotropic distillation (Scheme S1, in ESI†). Single crystals for Xray diffraction were obtained by slow evaporation of the solvent in air. In X-ray crystallographic analysis, the neodymium complex is observed to exist as a chloride-free coordination polymer. The structure consists of neodymium coordinated with three bidentate diethylphosphate (DEP) ligands in an octahedral geometry forming bridges connected to the nearby neodymium atoms (Fig. S1, in ESI†). This crystal structure has been reported previously. ${ }^{14,26,27}$ However, it is worth noting that the reported methods were focused only on growing single crystals for spatial structural analysis.

In contrast, our method can easily synthesize the neodymium catalyst in a preparative quantity and high purity. The neodymium catalyst is stable to air, water, and heat, and it is readily soluble in water. EDX analysis further demonstrated the neodymium-complex is halide-free and showed the content of oxygen: $37.03 \%$, neodymium: $3.87 \%$, carbon: $47.25 \%$ and phosphorus: $11.87 \%$ (Fig. S2 in ESI†).

The polymerization of $\beta$-myrcene was systematically investigated using the synthesized catalyst, $\left[\mathrm{Nd}(\mu-\mathrm{DEP})_{3}\right]_{x}$, and several controls, including the precursor $\left(\mathrm{NdCl}_{3} \cdot 6 \mathrm{H}_{2} \mathrm{O}\right)$ and both with and without TIBA as a co-catalyst, a control experiment using only TIBA, and the catalyst without TIBA. The experimental results are summarized in Table S1 in ESI. $\uparrow$ The results indicated that both $\mathrm{NdCl}_{3} \cdot 6 \mathrm{H}_{2} \mathrm{O}$ and $\left[\mathrm{Nd}(\mu-\mathrm{DEP})_{3}\right]_{x}$ were not catalytically active when used alone. The combination of $\mathrm{NdCl}_{3} \cdot 6 \mathrm{H}_{2} \mathrm{O}$ /TIBA likewise produced only a trace amount of polymer. The use of only TIBA resulted in a highly cross-linked insoluble polymer. However, the combination of $\left[\operatorname{Nd}(\mu-\mathrm{DEP})_{3}\right]_{x}$ and TIBA effectively efficiently polymerized $\beta$-myrcene. This catalytic system is similar to the Ziegler-Natta catalytic system and is active towards diene polymerization only in the presence of an organo-aluminum compound as a co-catalyst, with the exception that halides are not necessary for the polymerization.

Despite the lack of halides, our catalytic system exhibits relatively narrow molecular weight distribution $\left(M_{\mathrm{w}} / M_{\mathrm{n}}=1.8\right)$, and comparatively high cis-1,4 content up to $96 \%$ for the polymerization of $\beta$-myrcene. In contrast, other previously reported binary systems with an absence of halides produced large polydispersity indexes, bimodal molecular weight distributions, and much lower $c i s-1,4$ content. ${ }^{23,24}$

Several organoaluminum cocatalysts were tested, including triisobutylaluminum (TIBA), methyl aluminoxane (MAO), and the combination of TIBA/diethyl aluminum chloride (DEAC). However, TIBA is the most effective toward the polymerization of $\beta$-myrcene and results in the highest molecular weight with a relatively narrow PDI and highest content of cis-1,4. The neodymium to TIBA ratios were systematically varied to achieve the optimal conditions for polymerization, and the results are summarized in (Table 1, entry 1-6). The molar ratio of $[\mathrm{Nd}]:[\mathrm{TIBA}]=1: 30$ produced the best results for the polymerization of $\beta$-myrcene, producing a molecular weight of 13000 and PDI of 1.80 and affording cis-1,4 content of $96 \%$ (Table 1 , entry 5$)$. The synthesized poly( $\beta$-myrcene) was characterized by ${ }^{1} \mathrm{H}$ and ${ }^{13} \mathrm{C}$ NMR analysis (Fig. $\mathrm{S} 3$, in ESI $\dagger$ ). When polymerizing the diene monomers, typically three different microstructures of the polymers could occur that are cis-1,4, trans-1,4, and 3,4 isomers. The content of cis-1,4 and 3,4 isomers of poly( $\beta$-myrcene) was determined using ${ }^{1} \mathrm{H}$ NMR analysis by integrating the peak at $5.1 \mathrm{ppm}$ which is due to protons from the cis-1,4 product, against the peak at $4.9 \mathrm{ppm}$ which is corresponding to the protons from 3,4 incorporation. The presence of trans-1,4 incorporation can be identified in ${ }^{13} \mathrm{C}$ NMR at $131.6 \mathrm{ppm}$, however, with this catalytic system, no trans-1,4 incorporation of the poly( $\beta$-myrcene) was observed.

The molecular weight distribution is relatively narrow for this catalytic system. One possible reason for this could be that the reaction mixture becomes homogeneous upon addition of TIBA (Fig. S4, in ESI $\dagger$ ). This could be attributed to more alkyl

Table 1 Polymerization of $\beta$-myrcene using $\left[\mathrm{Nd}(\mu-\mathrm{DEP})_{3}\right]_{x} /$ TIBA at various molar ratios

\begin{tabular}{lllrr}
\hline Entry & {$[\mathrm{My}]_{0}:\left[\left[\mathrm{Nd}(\mu-\mathrm{DEP})_{3}\right]_{x}\right]_{0}:[\mathrm{TIBA}]_{0}$} & Conversion $(\%)$ & $M_{\mathrm{n}}\left(\mathrm{g} \mathrm{\textrm {mol } ^ { - 1 } )}\right.$ & PDI \\
\hline 1 & $250: 1: 3$ & 26 & 6835 & 2.38 \\
2 & $250: 1: 10$ & 27 & 3460 & 95 \\
3 & $250: 1: 20$ & 56 & 5950 & 95 \\
4 & $250: 1: 25$ & 74 & 9455 & 2.45 \\
5 & $250: 1: 30$ & 98 & 13000 & 2.35 \\
6 & $250: 1: 35$ & 98 & 5265 & 95 \\
\end{tabular}


Table 2 Effects of increasing $\beta$-myrcene to Neodymium catalyst ratio

\begin{tabular}{lllll}
\hline Entry & {$[\mathrm{M}]_{0}:\left[\left[\mathrm{Nd}(\mu-\mathrm{DEP})_{3}\right]_{x}\right]_{0}:[\mathrm{TIBA}]_{0}$} & Conversion $(\%)$ & $M_{\mathrm{n}}\left(\mathrm{g} \mathrm{mol}^{-1}\right)$ & PDI \\
\hline 1 & $150: 1: 30$ & 95 & 6700 & 2.25 \\
2 & $250: 1: 30$ & 98 & 13000 & 96 \\
3 & $500: 1: 30$ & 98 & 27125 & 96 \\
4 & $1000: 1: 30$ & 60 & 48500 & 3.88 \\
\end{tabular}

(a)

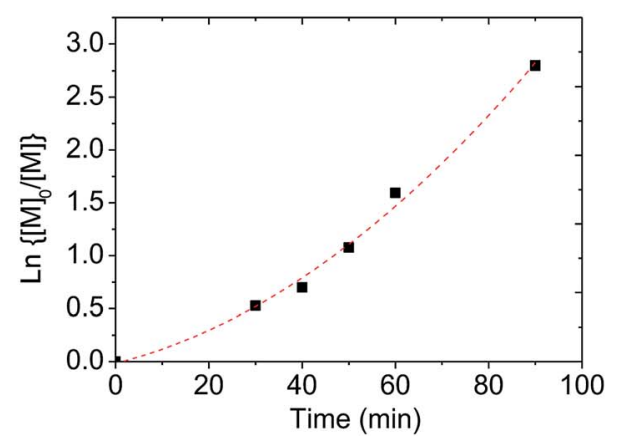

(b)

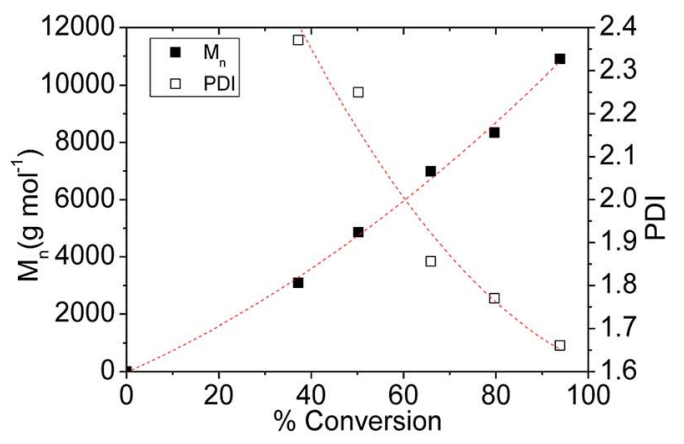

Fig. 1 (a) Logarithm of monomer conversion versus time, (b) $M_{n}$ and PDI versus conversion. Reaction conditions: room temperature, at the molar ratio of $[\mathrm{M}]:\left[\left[\mathrm{Nd}(\mu-\mathrm{DEP})_{3}\right]_{x}\right]:[\mathrm{Al}]=250: 1: 30$.

segments from TIBA coordinated to the metal, which increases the solubility. The mixture remains homogenous after the addition of monomer. Because of this, each active site is identical and immediately available, without concerns of microenvironment effects or the catalyst becoming more accessible over time. Consequently, the molecular weight distribution is narrower than in a heterogeneous system.

To probe the polymerization behavior, the polymerization of $\beta$-myrcene with $\left[\mathrm{Nd}(\mu-\mathrm{DEP})_{3}\right]_{x}$ catalyst was performed at room temperature with various molar ratios of monomer to neodymium catalyst to TIBA co-catalyst including $150: 1: 30$, $250: 1: 30,500: 1: 30$, and $1000: 1: 30$ to evaluate the dependence of molecular weight on the monomer to initiator ratio (Table 2, entry 1-4). It is observed that the molecular weight of the synthesized poly( $\beta$-myrcene) depended on the molar ration of monomer to neodymium and increased with increasing $\beta$-myrcene to neodymium ratio. For example, the ratio of $150: 1$ produced a molecular weight of polymer $6700 \mathrm{~g}$ $\mathrm{mol}^{-1}$ (Table 2, entry 1), and increasing the ratio to $1000: 1$, the molecular weight of polymer increased to $48500 \mathrm{~g} \mathrm{~mol}^{-1}$ (Table 2 , entry 4). The molecular weight versus the monomer to initiator ratio plot is shown in Fig. S5 in ESI. $\dagger$ The observed molecular weight in SEC is lower than the predicted molecular weight could be in part due to the difference between the hydrodynamic volume of poly( $\beta$-myrcene) and the polystyrene standard that was used to calibrate the SEC.

Kinetic studies were performed using a molar ratio of [Nd] : [TIBA] : $\left[\beta\right.$-myrcene] $=1: 30: 250$ at $24{ }^{\circ} \mathrm{C}$ over two hours. The slight deviation from linearity in Fig. 1a could indicate the presence of some termination reaction, and a slow initiation based on the shape of the logarithm of the monomer conversion plot. Similarly, slow initiation was also observed in a previously reported catalytic system containing $\mathrm{NdCl}_{3} \cdot 3 \mathrm{TEP}$ in our group. ${ }^{14}$ The polydispersity index decreases as the conversion increases, as shown in Fig. 1b. The number average molecular weight as a function of conversion deviated slightly from linearity (Fig. 1b), indicating a small contribution of chain transfer reactions, a departure from ideal living polymerization behavior. Therefore, we consider this catalytic system is pseudo-living. The conversion versus time plot (Fig. S6 in ESI†) indicates the conversion of monomer reached approximately $95 \%$ in two hours.

Chain extension experiments further demonstrate the living behavior of the $\left[\mathrm{Nd}(\mu-\mathrm{DEP})_{3}\right]_{x} / \mathrm{TIBA}$ catalytic system. The initial

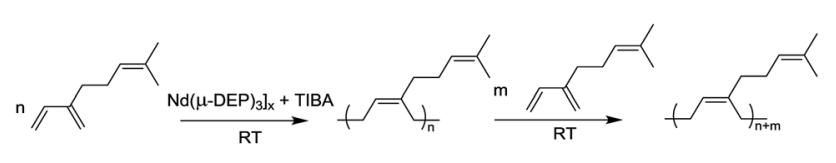

$[\mathrm{Nd}]:[\mathrm{TIBA}]:[\beta$-myrcene 1]:[$[\beta$-myrcene 2] $=1: 30: 150: 300$

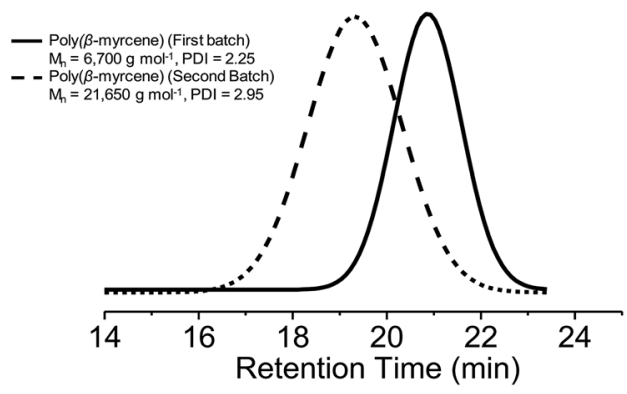

Fig. 2 SEC curves for chain extension of poly( $\beta$-myrcene). The black curve indicates the $1^{\text {st }}$ batch of poly $(\beta$-myrcene) and the dotted curve indicates after polymerization of a $2^{\text {nd }}$ portion of $\beta$-myrcene. 
$\mathrm{n}$

(a)
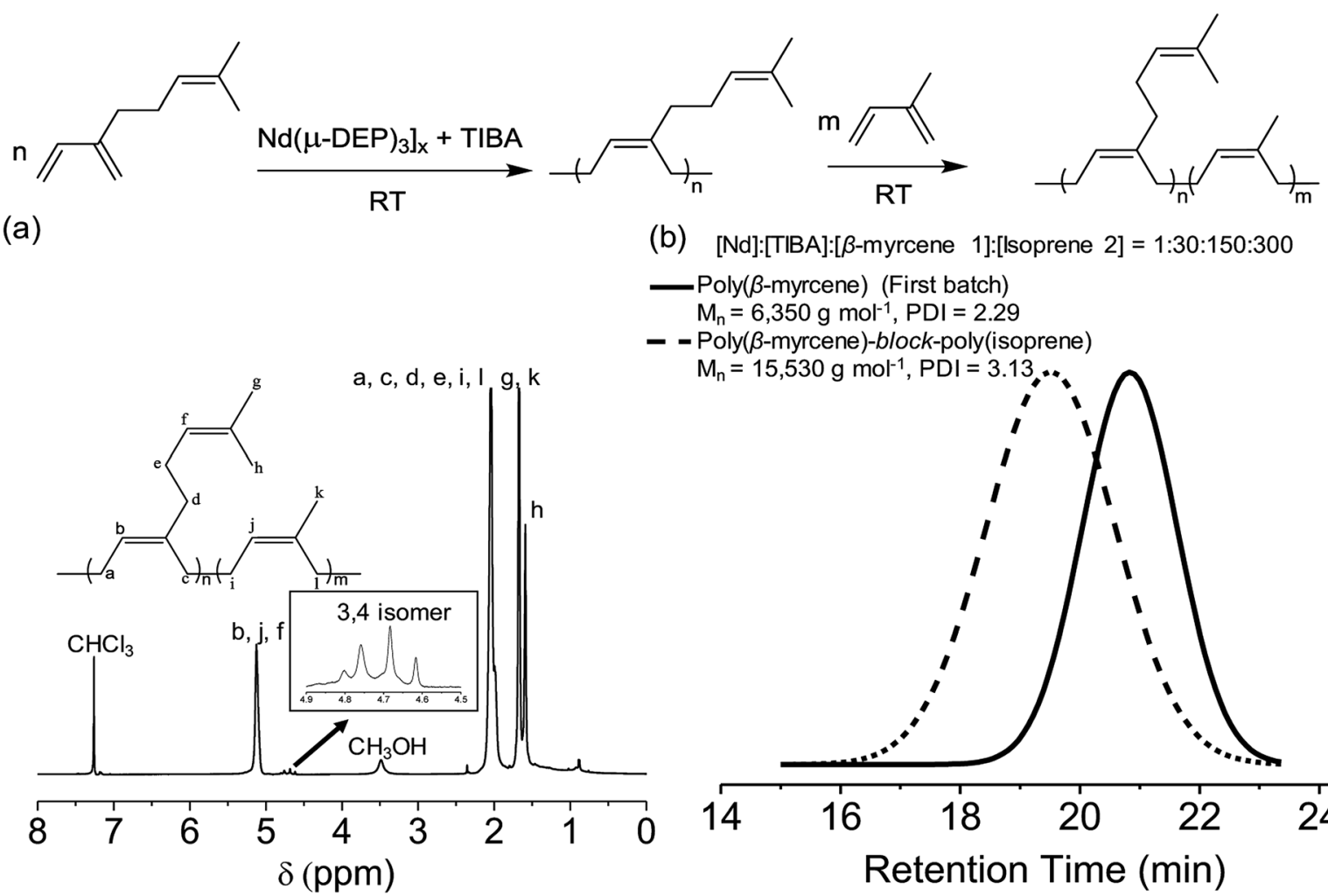

(b) [Nd]:[TIBA]:[ $\beta$-myrcene 1]:[lsoprene 2] = 1:30:150:300

$$
\begin{gathered}
\text { Poly }(\beta \text {-myrcene) (First batch) } \\
\mathrm{M}_{\mathrm{n}}=6,350 \mathrm{~g} \mathrm{~mol}^{-1}, \mathrm{PDI}=2.29 \\
\text { - - Poly( } \beta \text {-myrcene)-block-poly(isoprene) }
\end{gathered}
$$$$
\mathrm{M}_{\mathrm{n}}=15,530 \mathrm{~g} \mathrm{~mol}^{-1}, \mathrm{PDI}=3.13
$$

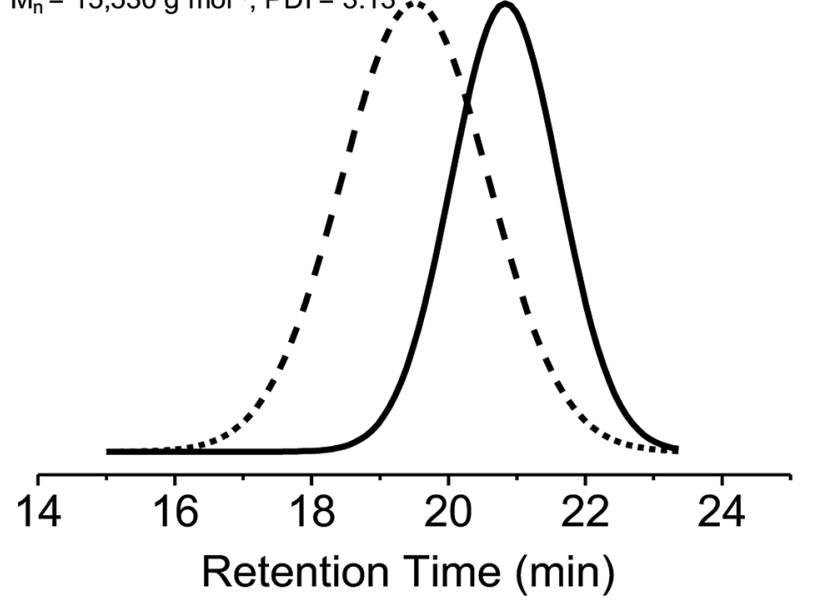

Fig. 3 (a) ${ }^{1} \mathrm{H}$ NMR of block copolymer poly( $\beta$-myrcene)- $b$-poly(isoprene). (b) SEC curves of poly( $\beta$-myrcene)- $b$-poly(isoprene). The dotted curve indicates the poly $\left(\beta\right.$-myrcene) and the solid curve indicates the block copolymer. Reaction condition: $\left[\left[N d(\mu-D E P)_{3}\right]_{x}\right]:[T I B A]:\left[\beta-m_{3} y r c e n e\right.$ 1] : [isoprene 2] $=1: 30: 150: 300$ at room temperature.

portion of monomer was polymerized at a molar ratio of $[\beta-$ myrcene $]:\left[\left[\mathrm{Nd}(\mu-\mathrm{DEP})_{3}\right]_{x}\right]:[\mathrm{TIBA}]=150: 1: 30$. Upon the complete consumption of the monomer, the second portion of $\beta$-myrcene, twice the amount of the first batch (300 equivalents), was introduced. If the catalytic system exhibited living character, the molecular weight after the complete consumption of the second portion of the monomer is expected to triple. The SEC traces shown in Fig. 2 indicated the monomodal distribution and the molecular weight increase from $6700 \mathrm{~g} \mathrm{~mol}^{-1}$ to $21650 \mathrm{~g} \mathrm{~mol}^{-1}$ after the addition of the second portion of $\beta$ myrcene. The small tailing observed in the low molecular weight on the SEC traces indicated the slow initiation.

Evidence of living behavior was also demonstrated by the synthesis of a well-defined poly( $\beta$-myrcene)-block-poly(isoprene) block copolymer by sequential introduction of $\beta$-myrcene and isoprene to the initiator/catalyst generated from $\left[\mathrm{Nd}(\mu-\mathrm{DEP})_{3}\right]_{x}$ and TIBA with a molar ratio of $[\beta$-myrcene $]:[$ isoprene $]:[[\mathrm{Nd}(\mu-$ $\left.\left.\mathrm{DEP})_{3}\right]_{x}\right]:[\mathrm{TIBA}]=150: 300: 1: 30$. The first block, $\operatorname{poly}(\beta-$ myrcene), was synthesized to generate a polymer with $M_{\mathrm{n}}=$ $6350 \mathrm{~g} \mathrm{~mol}^{-1}$ and PDI $=2.29$. After complete consumption of $\beta$ myrcene, 300 equivalents of isoprene were introduced to generate the second block of the polymer with $M_{\mathrm{n}}=15530$ and PDI $=3.13$. The ${ }^{1} \mathrm{H}$ NMR spectrum of poly( $(\beta$-myrcene $)$-blockpoly(isoprene) copolymer is shown in Fig. 3a and estimated to contain the composition of $25 \mathrm{~mol} \%$ of poly( $\beta$-myrcene) and $75 \mathrm{~mol} \%$ of poly(isoprene). The SEC traces of the polymer both before and after the addition of the second monomer are both monomodal (Fig. 3b). Thus, we can claim that a single polymer product was produced rather than a mixture of two separate polymer populations.

\section{Conclusions}

A halide-free neodymium-based binary catalyst system consisting of $\left[\mathrm{Nd}(\mu \text {-DEP })_{3}\right]_{x}$ and TIBA was synthesized and tested for the polymerization of $\beta$-myrcene. The structure and composition of the catalyst were confirmed by the single crystal X-ray diffraction and the EDX. This binary neodymium catalyst system displayed good catalytic activity. The resulting poly $(\beta$ myrcene) exhibited high cis-1,4 content and relatively narrow molecular weight distribution $\left(M_{\mathrm{w}} / M_{\mathrm{n}}=1.80\right)$. The kinetic studies confirmed the catalyst system to be pseudo-living with slow initiation.

Further livingness behavior was demonstrated by the successful synthesis of block copolymer poly( $\beta$-myrcene)- $b$-poly(isoprene). These results are unusual for a halide-free system, as halides are generally required for good performance in these Ziegler-Natta type catalytic systems. These results show that this is not strictly the case and suggest that worthwhile catalytic systems can be found in compositions that previously would not have been considered.

\section{Conflicts of interest}

The authors declare no competing financial interest. 


\section{Acknowledgements}

We gratefully thank the National Science Foundation (CHE1566059) and Welch Foundation (AT-1740) for financially supporting of this project.

\section{References}

1 P. Joseph and J. R. Ebdon, Recent Developments in FlameRetarding Thermoplastics and Thermosets, in Fire Retardant Materials, ed. A. R. Horrocks and D. Price, Woodhead Publishing, 2001, p. 220.

2 Y. Ikeda, Understanding Network Control by Vulcanization for Sulfur Cross-Linked Natural Rubber (Nr), in Chemistry, Manufacture, and Applications of Natural Rubber, ed. S. Kohjiya and Y. Ikeda, Woodhead Publishing, 2014, p. 119.

3 S. Ebnesajjad, Surface Preparation of Thermoplastics, Thermosets, and Elastomers, in Handbook of Adhesives and Surface Preparation, ed. S. Ebnesajjad, William Andrew Publishing, Oxford, 2011, p. 107.

4 L. Friebe, O. Nuyken and W. Obrecht, Neodymium-Based Ziegler/Natta Catalysts and Their Application in Diene Polymerization, in Neodymium Based Ziegler Catalysts Fundamental Chemistry, ed. O. Nuyken, Springer, Berlin, Heidelberg, 2006, p. 1.

5 Z. Zhang, D. Cui, B. Wang, B. Liu and Y. Yang, Polymerization of 1,3-Conjugated Dienes with Rare-Earth Metal Precursors, in Molecular Catalysis of Rare-Earth Elements, ed. P. W. Roesky, Springer, Berlin, Heidelberg, 2010, p. 49.

6 D. M. Roitershtein, A. A. Vinogradov, A. A. Vinogradov, K. A. Lyssenko, Y. V. Nelyubina, I. V. Anan'ev, I. E. Nifant'ev, V. A. Yakovlev and N. N. Kostitsyna, Organometallics, 2013, 32, 1272.

7 J. Liu, X. Fan, X. Min, X. Zhu, N. Zhao and Z. Wang, RSC Adv., 2018, 8, 21926.

8 W. Gao and D. Cui, J. Am. Chem. Soc., 2008, 130, 4984.

9 N. G. Marina, Y. B. Monakov, S. R. Rafikov and K. K. Gadeleva, Polym. Sci. U.S.S.R., 1984, 26, 1251.
10 L. Porri, G. Ricci, A. Giarrusso, N. Shubin and Z. Lu, Recent Developments in Lanthanide Catalysts for 1,3-Diene Polymerization, in Olefin Polymerization, American Chemical Society, 1999, vol. 749, p. 15.

11 S. Zhiquan, O. Jun, W. Fusong, H. Zhenya, Y. Fusheng and Q. Baogong, J. Polym. Sci., Polym. Chem. Ed., 1980, 18, 3345.

12 G.-l. Li, C.-y. Ren, W.-m. Dong, L.-s. Jiang, X.-q. Zhang and F.-s. Wang, Chin. J. Polym. Sci., 2010, 28, 157.

13 Y. Hu, C. Zhang, X. Liu, K. Gao, Y. Cao, C. Zhang and X. Zhang, J. Appl. Polym. Sci., 2014, 131, 40153.

14 R. N. Kularatne, A. Yang, H. Q. Nguyen, G. T. McCandless and M. C. Stefan, Macromol. Rapid Commun., 2017, 38, 1700427.

15 Y. Ren, R. N. Kularatne, J. T. Miller, S. T. Polderman, T. D. Vo, M. C. Biewer and M. C. Stefan, J. Polym. Sci., Part A: Polym. Chem., 2018, 56, 1289.

16 J. H. Yang, M. Tsutsui, Z. Chen and D. E. Bergbreiter, Macromolecules, 1982, 15, 230.

17 H. Guo, J. Bi, J. Wang, X. Zhang, S. Jiang and Z. Wu, Polymer, 2017, 119, 176.

18 X. Jia, Y. Hu, Q. Dai, J. Bi, C. Bai and X. Zhang, Polymer, 2013, 54, 2973.

19 A. Oehme, U. Gebauer, K. Gehrke, P. Beyer, B. Hartmann and M. D. Lechner, Macromol. Chem. Phys., 1994, 195, 3773.

20 Q. Zhang, W. Li and Z. Shen, Eur. Polym. J., 2002, 38, 869.

21 D. Barbier-Baudry, O. Blacque, A. Hafid, A. Nyassi, H. Sitzmann and M. Visseaux, Eur. J. Inorg. Chem., 2000, 2000, 2333.

22 F. Bonnet, M. Visseaux, A. Pereira and D. Barbier-Baudry, Macromolecules, 2005, 38, 3162.

23 W. J. Evans and D. G. Giarikos, Macromolecules, 2004, 37, 5130.

24 W. Dong and T. Masuda, J. Polym. Sci., Part A: Polym. Chem., 2002, 40, 1838.

25 M. Suhaj, J. Food Compos. Anal., 2006, 19, 531.

26 M. Rafizadeh, V. Amani and N. S. Mortazavi, Bull. Korean Chem. Soc., 2009, 30, 489.

27 V. G. Lebedev, K. K. Palkina, S. I. Maksimova, E. N. Lebedeva and O. V. Galaktionova, Zh. Neorg. Khim., 1982, 27, 2980. 